\title{
Erratum to: Mapping of earthworm distribution for the British Isles and Eire highlights the under- recording of an ecologically important group
}

\author{
Daniel Carpenter $\cdot$ Emma Sherlock $\cdot$ David T. Jones $\cdot$ Jim Chiminoides • \\ Thomas Writer • Roy Neilson • Brian Boag • Aidan M. Keith • \\ Paul Eggleton
}

Published online: 3 June 2012

(C) Springer Science+Business Media B.V. 2012

\section{Erratum to: Biodivers Conserv (2012) 21:475-485 DOI 10.1007/s10531-011-0194-x}

Unfortunately, the legends of Figs. 3 and 4 were interchanged and hence incorrectly published in the original publication of the article. The correct legends with their figures are reproduced below.

The online version of the original article can be found under doi:10.1007/s10531-011-0194-x.

D. Carpenter $(\bowtie) \cdot$ D. T. Jones · P. Eggleton

Soil Biodiversity Group, Department of Entomology, The Natural History Museum, Cromwell Road, London SW7 5BD, UK

e-mail: d.carpenter@nhm.ac.uk

E. Sherlock · J. Chiminoides - T. Writer

Department of Zoology, The Natural History Museum, Cromwell Road, London SW7 5BD, UK

R. Neilson · B. Boag

The James Hutton Institute, Invergowrie, Dundee DD2 5DA, UK

A. M. Keith

Centre for Ecology \& Hydrology, Lancaster Environment Centre, Library Avenue, Bailrigg,

Lancaster LA1 4AP, UK

A. M. Keith

School of Biology \& Environmental Science, University College Dublin, Belfield, Dublin, Ireland 


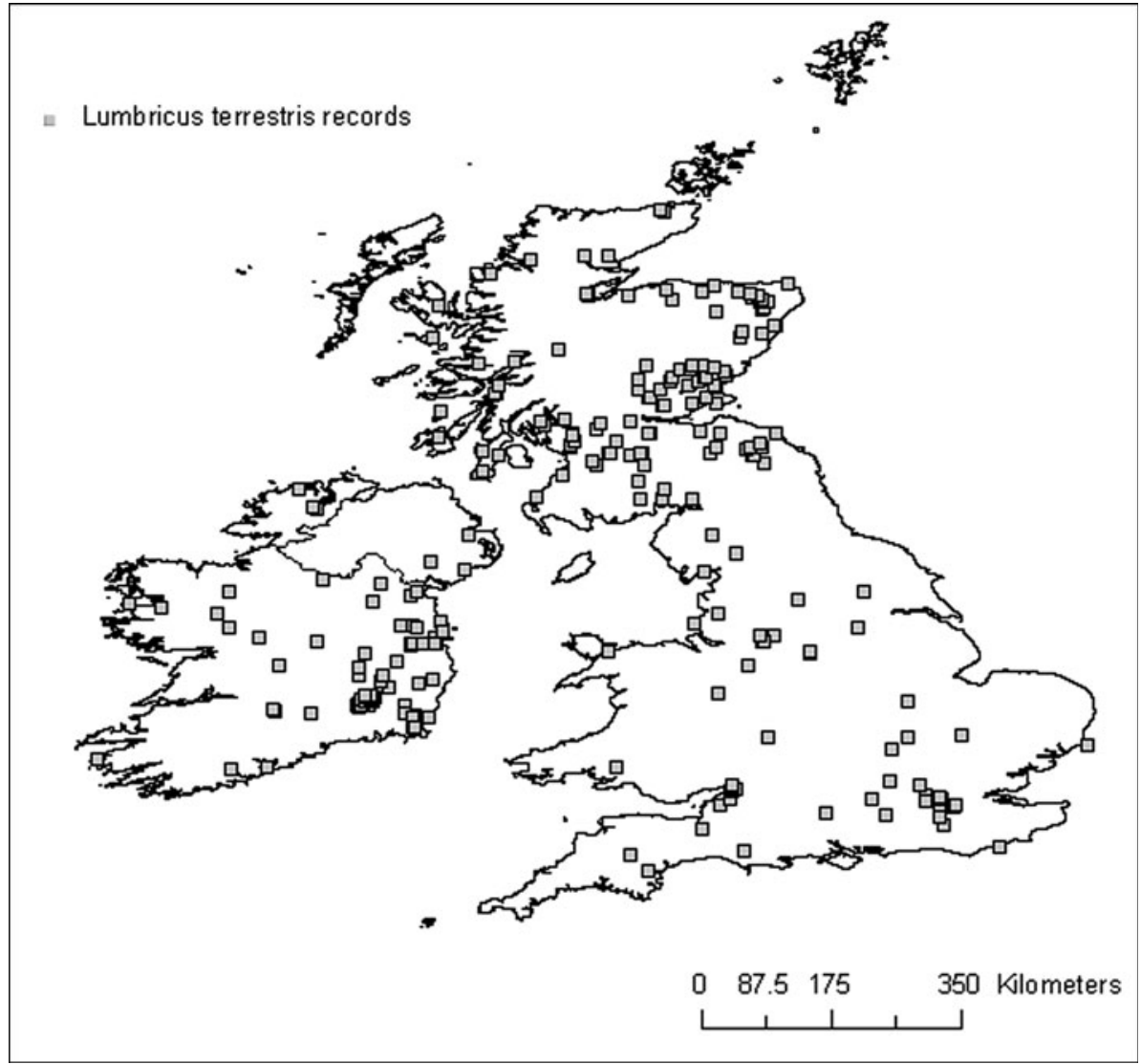

Fig. 3 Distribution of Lumbricus terrestris records in the United Kingdom and Eire 


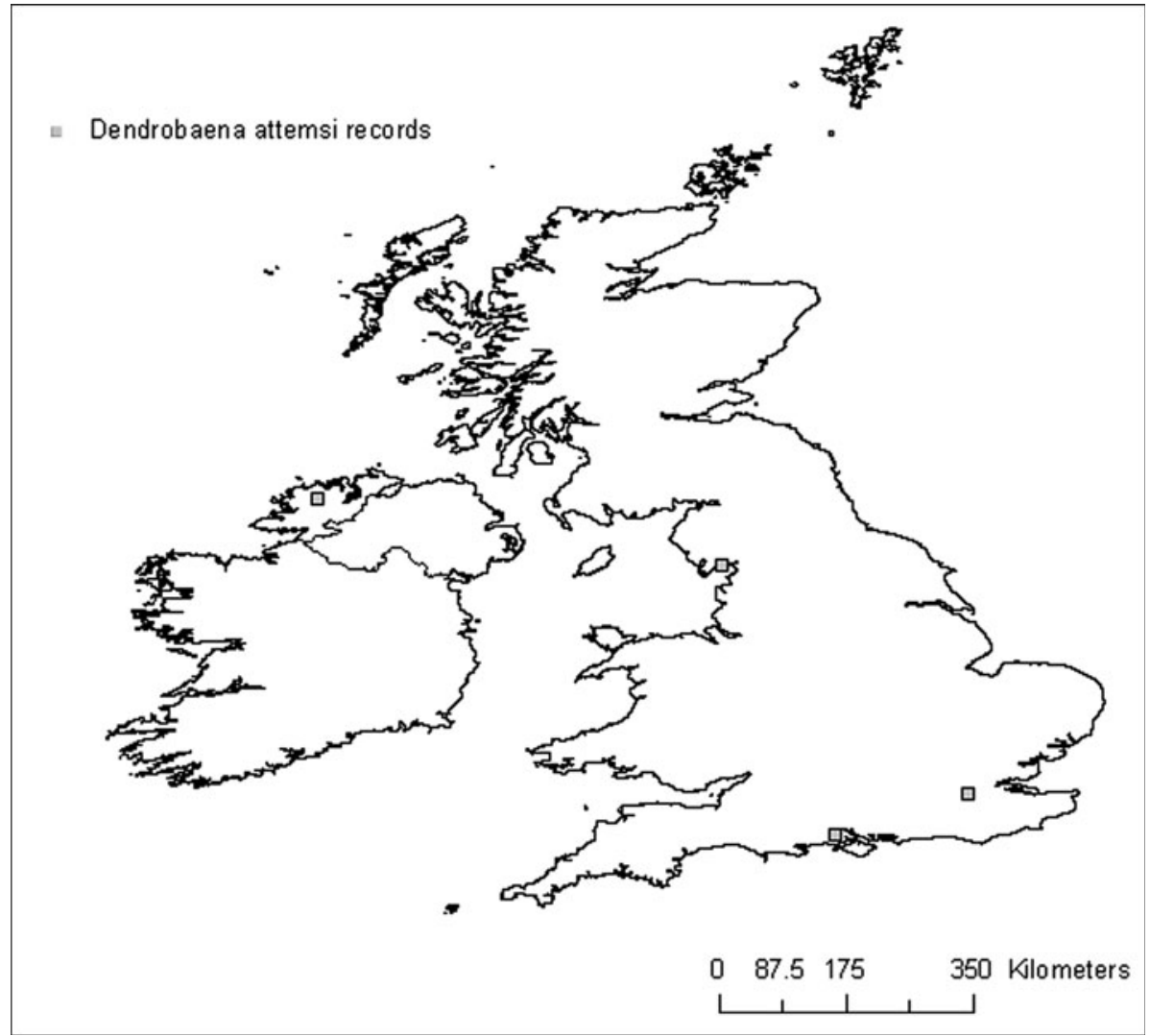

Fig. 4 Distribution of Dendrobaena attemsi records in the United Kingdom and Eire 